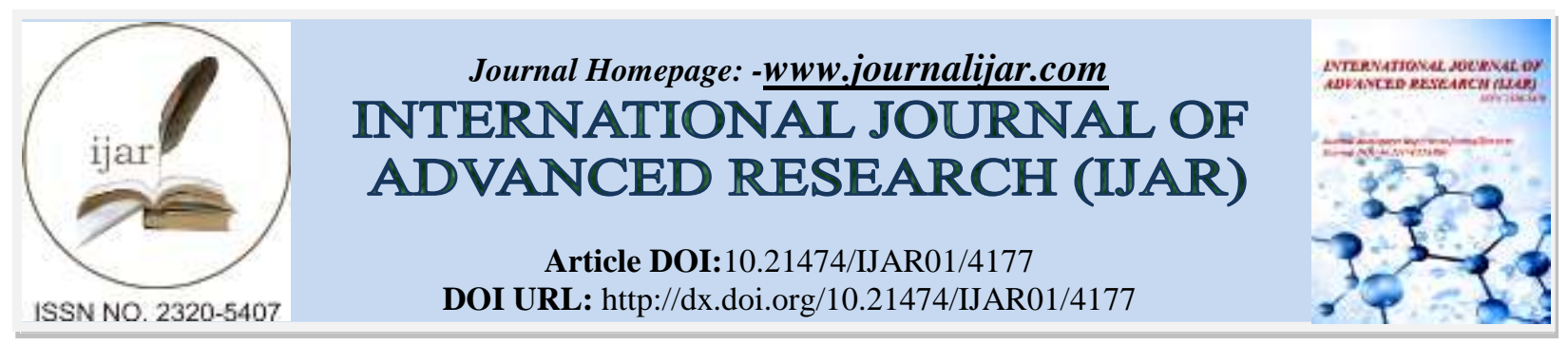

RESEARCH ARTICLE

\title{
SHORT TERM SUCCESSFUL ORTHOSURGICAL MANAGEMENT OF AN ADULT CLASS II DIV1 MALOCCLUSION
}

Shweta Airan, Rekha Sharma, Manish Airan, Amit Dahiya and Lekha Sharma.

\section{Manuscript Info}

Manuscript History

Received: 11 March 2017

Final Accepted: 12 April 2017

Published: May 2017

\begin{abstract}
One of the most common malocclusion encountered in clinical practice is Class II malocclusion. Treatment options range from functional appliances in growing children to orthognathic surgery in adult patients while choosing camouflage in others. This case report presents successful management of an adult Class II div 1 malocclusion with orthodontic fixed appliance and mandibular advancement surgery, treated within a period of 9 months.
\end{abstract}

Copy Right, IJAR, 2016,. All rights reserved.

\section{Introduction:-}

Class II div 1 malocclusion is more prevalent than any type of malocclusion after Class I malocclusion in our country. ${ }^{(1)}$ Bilateral sagittal split osteotomy is the most common surgical procedure followed in adult Class II div 1 malocclusion patients. ${ }^{(2)}$ From reducing the treatment time to the most favourable skeletal results are its advantages over conventional functional appliance therapy. This case report presents successful management of a patient with Class II div 1 malocclusion treated with mandibular advancement surgery within a period 9 months

\section{Pretreatment Diagnosis:-}

A 17-year-old adult male reported to the department of orthodontics and dentofacial orthopaedics with chief complain of forwardly placed upper front teeth. Extraorally, the patient had no apparent facial asymmetry. He had leptoprosopic facial form and convex facial profile. The chin was recessive with potentially incompetent lips. During smile large buccal corridors were seen which indicate possibly constricted arches. The temporomandibular joints were normal. The clinical FMA was average, and he had positive visual treatment objective on the advancement of the mandible.

Intraorally, the patient presented presence of all permanent teeth except missing left lower second molar and all third molars. He had a Class II division 1 incisor relationship, increased overjet of 9mm, overbite of $6 \mathrm{~mm}$.. The molar and canine relationships were full unit Class II on both sides. The maxillary incisors were proclined and protrusive. The arch was constricted in the anterior region. There was mild crowding in the mandibular arch. Oral hygiene was good with no active carious lesion.

Orthopantomogram confirmed the absence of 37 and tooth buds of all third molars. Also patient denied any extraction of molars.

Growth Status: CVMI 6, SMI 12

In the cephalometric assessment, the increased ANB $\left(7^{\circ}\right)$ and wits appraisal $(+10 \mathrm{~mm})$ confirmed that the patient had a Class II skeletal pattern. The normal SNA and reduced SNB indicated a normal maxilla, receding mandible, 
and chin. SN-mandibular plane angle $\left(29.5^{\circ}\right)$ and Jarabak's ratio $(63.8 \%)$ indicated an average growth pattern. The upper incisors were proclined, whereas the lower incisors were upright.

\section{Treatment Objectives:-}

1. To improve convex facial profile.

2. To decrease negative spaces (buccal corridors) and improve smile

3. To achieve Class I molar, canine and incisor relationship relationship.

4. To achieve normal overjet and overbite

\section{Treatment Plan:-}

Clinical examination and cephalometric findings show that this 17 year old adult male has skeletal Class II jaw bases with orthognathic maxilla, retrognathic mandible and receding chin and an underlying average growth pattern. Considering all the factors orthosurgical treatment plan was finalized. Orthodontic phase involve nonextraction alignment and leveling of both arches using broad archwires for the expansion of arches. Surgical plan involved mandibular advancement using bilateral sagittal split osteotomy.

\section{Treatment progress:-}

Case was started initially with bonding of only upper arch due to deepbite and constricted maxillary arch. To level the bite and facilitate bonding of lower arch, removable anterior bite plane was given with which patient showed excellent compliance. Leveling and aligning was done using $0.016 \mathrm{NiTi}$ archwires, followed by 0.017 x $0.025 \mathrm{NiTi}$, $0.019 \times 0.025 \mathrm{NiTi}$ and $0.019 \times 0.025 \mathrm{SS}$ archwire.

Presurgical orthodontics: After leveling and aligning of the both upper and lower arches were stabilized with 0.021 $\times 0.025$ SS arch wire. Case was decompensated into Class II molar and Class II canine relation bilaterally, with an overjet of $9 \mathrm{~mm}$, Face bow records were taken and a surgical splint was designed for mandibular advancement. Leveling and alignment of arches took 6 months.

\section{Surgical Procedure:-}

Mandibular advancement using bilateral sagittal split osteotomy followed by stabilization with monocortical screws was done.

\section{Postsurgical orthodontics:-}

After 2 weeks of surgery root paralleling was carefully done and cuspal settling was done using settling elastics over 0.014 Niti archwires. Total treatment time was 9 months

\section{Retention:-}

Upper Beggs wrap around retainer and lower hawleys retainer.

\section{Treatment Resuts:-}

The treatment objectives were achieved. The posttreatment facial profile of the patient demonstrated noticeable improvement with good facial esthetics, straight facial profile, and balanced competent lips. The intraoral occlusion revealed satisfactory result with characteristics of well-aligned dentition. Overjet and overbite were reduced to 3 $\mathrm{mm}$ and $2.5 \mathrm{~mm}$, respectively. Class I canine and molar relationship with good buccal interdigitation were also achieved.

During treatment, SNA value remained same, whereas the SNB value increased by $4^{\circ}$. As a consequence, the ANB value decreased by $4^{\circ}$ toward Class I skeletal pattern. The upper incisor proclination was slightly reduced, and lower incisor proclination was slightly increased. The lateral cephalometric superimposition was compared between pretreatment, presurgical, and postsurgical treatment. Superimposition demonstrated that maxillary molar remained stable and mandibular incisor and molar were moved mesially.

\section{Discussion:-}

Numerous methods treating Class II, division I malocclusion have been reported. To achieve best results in adult patients orthosurgical treatment is preferred. Although dental results can be achieved in such patients with fixed functional appliances but their stability remains questionable. ${ }^{(3)}$ The case reported in this article is an adult male patient in the completion stage of growth (CVMI 6). The patient was an ideal choice for orthosurgical treatment, 
imparting most favourable results in the shortest time period possible. Mandibular surgery with the Bilateral Sagittal Split surgical technique is the most commonly used mandibular osteotomy. It involves cuts on both sides of the mandible distal to the second molars and results in the mandible separating into three pieces, two posteriorly with the condyles and one anterior section. Orthodontic camouflage by extraction of upper premolars could have been another treatment option but was not considered for a number of reasons. The patient and his parents were keen to avoid extractions due to concerns about removing healthy teeth. Extraction of upper premolar teeth might be able to retract the upper protrusive lip and improve facial convexity to a certain extent, but would not improve mandibular retrognathism.

\section{Long-term Prognosis:-}

The prognosis for stability is good as the patient's growth pattern is favorable. Good buccal interdigitation and incisal contact also helped to stabilize the occlusal stability.

Figure 1:- Pretreatment photographs.

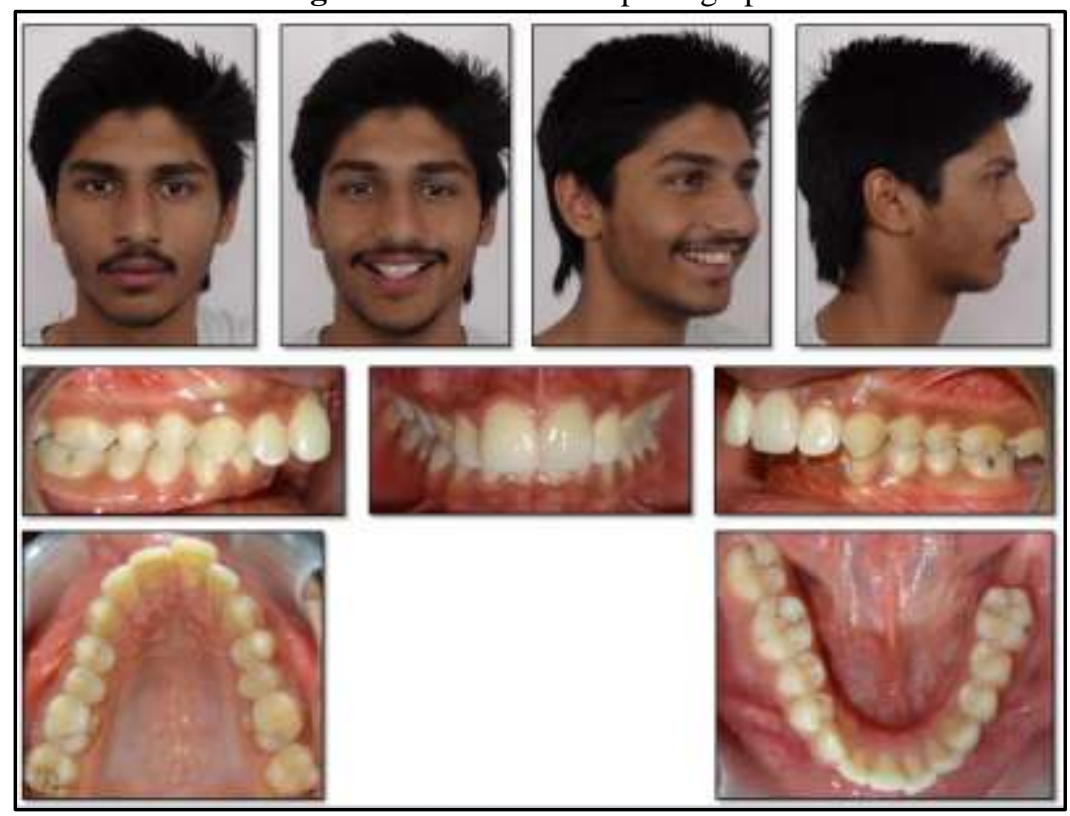

Figure 2:- Pretreatment OPG and Lateral cephalogram.

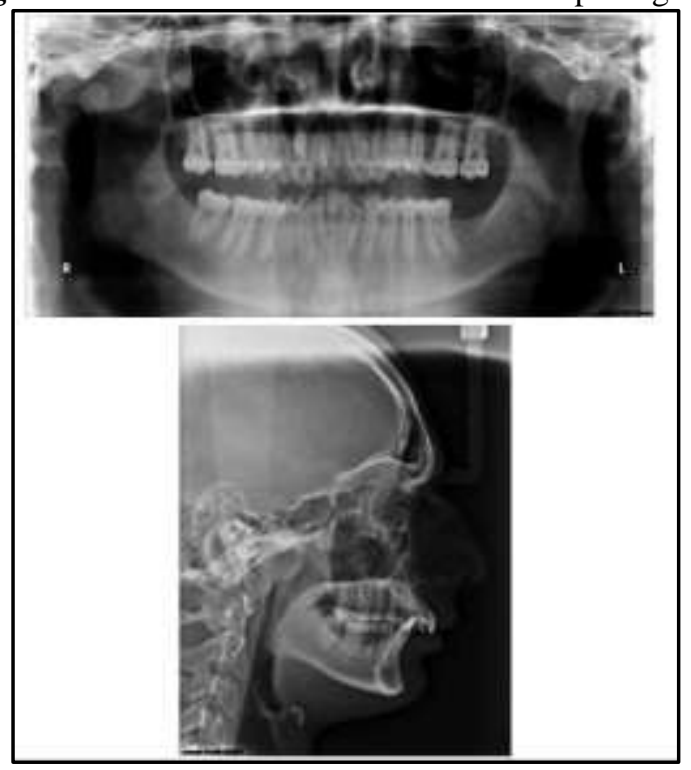


Figure 3:- Presurgical photographs.

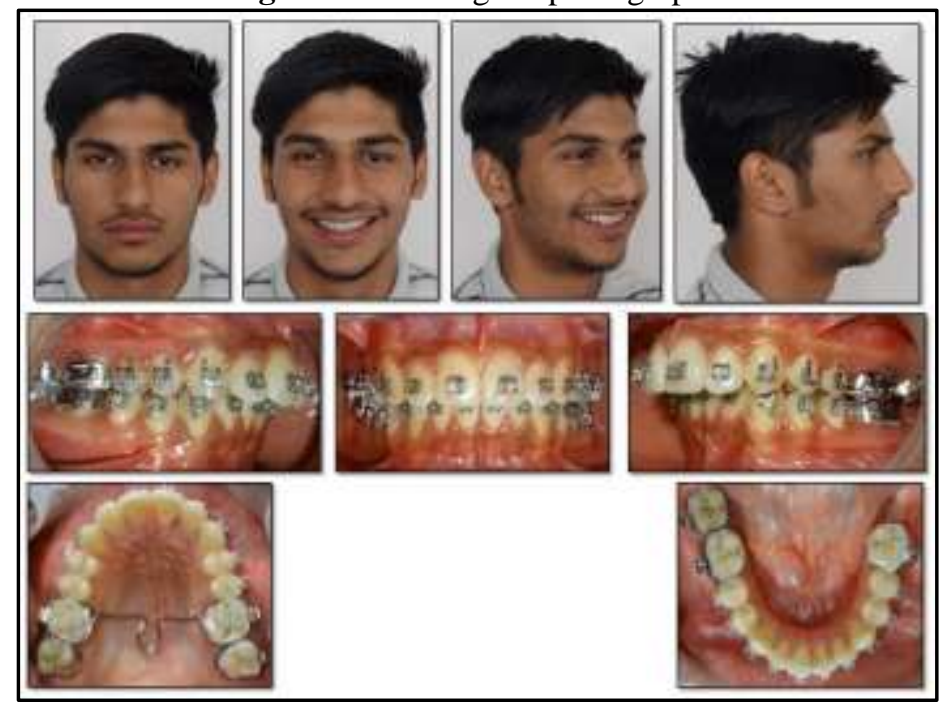

Figure 4:- Presurgical OPG and Lateral cephalogram.

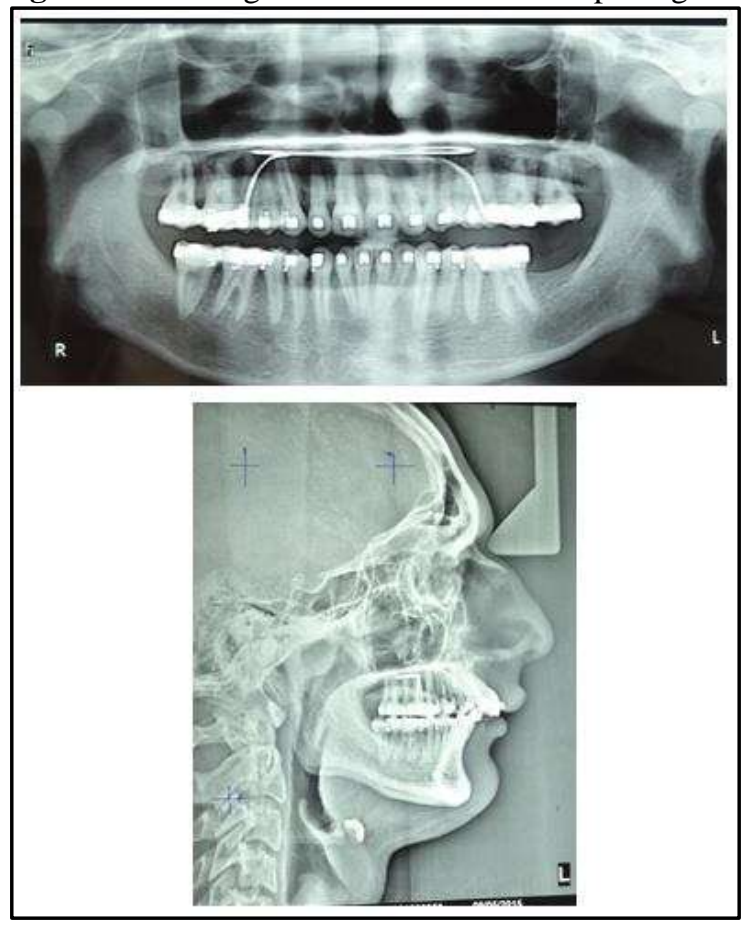


Figure 5:- Posttreatment photographs.

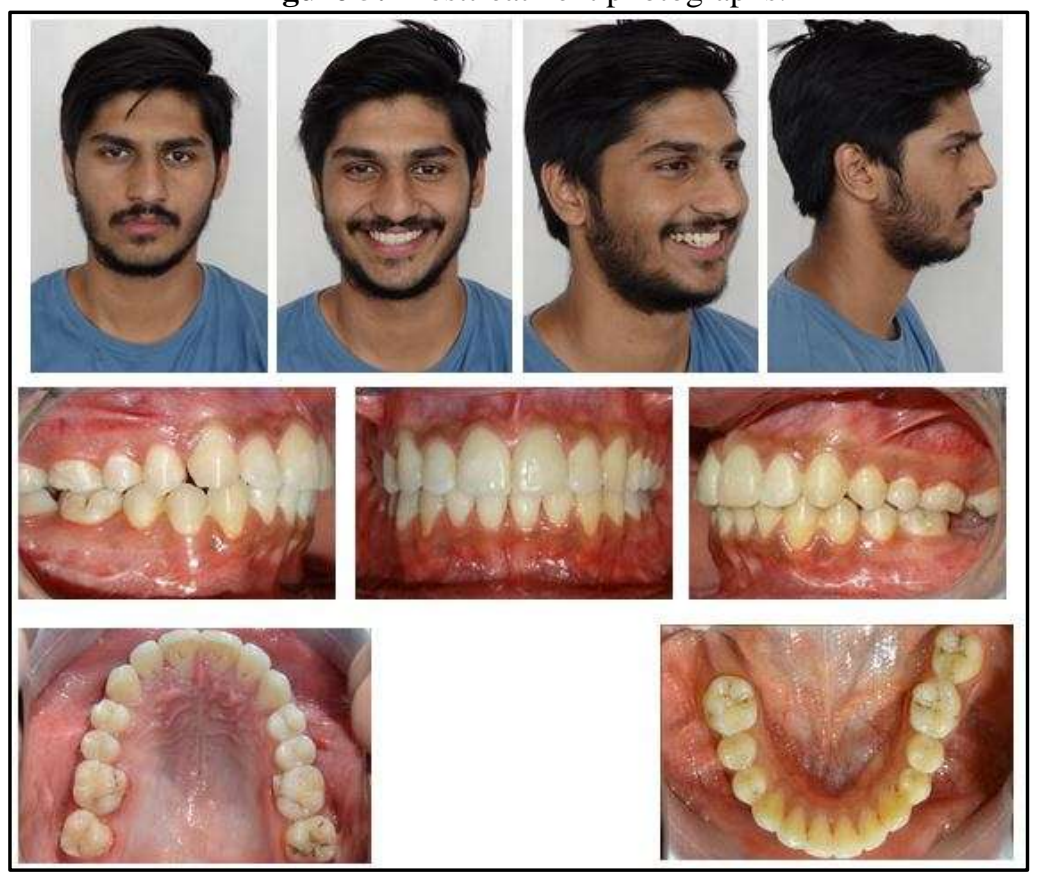

Figure 6:- Posttreatment OPG and Lateral cephalogram.
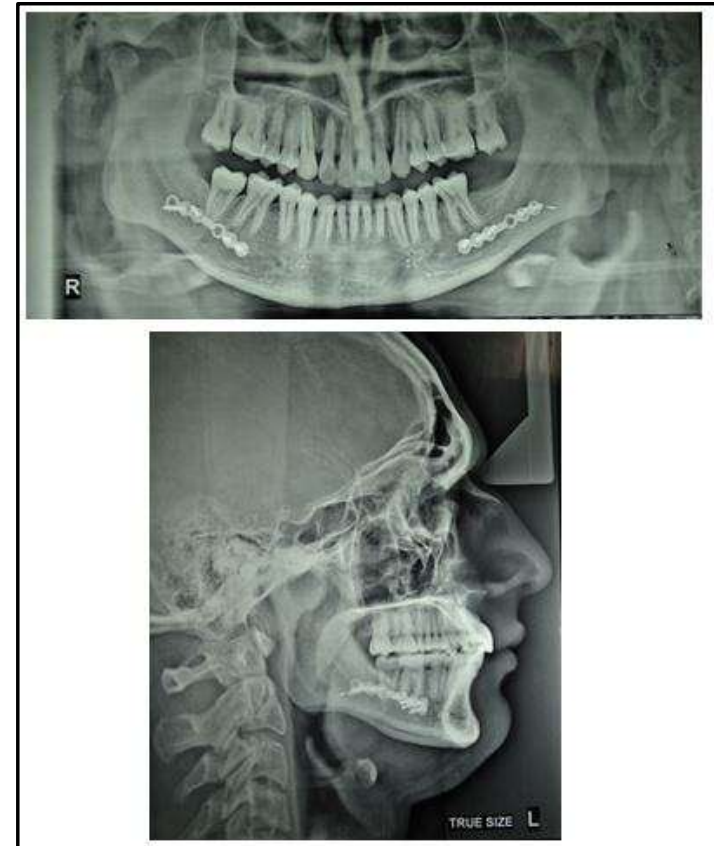
Figure 7:- Superimposition.

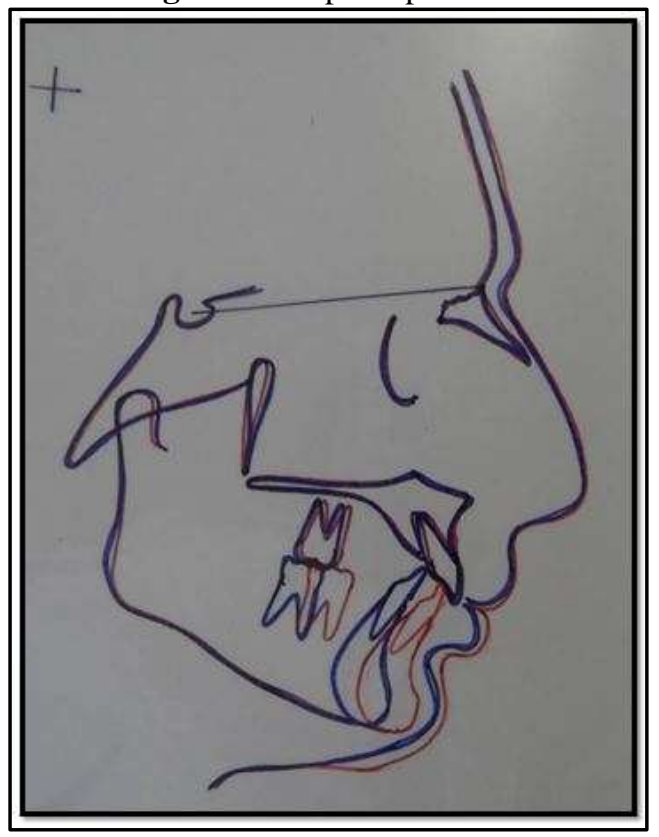

Table 1:- Skeletal Changes.

\begin{tabular}{|c|c|c|c|}
\hline & \multicolumn{3}{|c|}{ CASE 1 } \\
\hline & Pre (T0) & $\begin{array}{c}\text { Prefunctional } \\
\text { (after space closure) (T1) }\end{array}$ & $79^{\circ}$ \\
\hline SNA & $79^{\circ}$ & $79^{\circ}$ & $75^{\circ}$ \\
\hline SNB & $72^{\circ}$ & $8^{\circ}$ & $4^{\circ}$ \\
\hline ANB & $7^{\circ}$ & $11 \mathrm{~mm}$ & $76 \mathrm{~mm}$ \\
\hline Wits & $10 \mathrm{~mm}$ & $73 \mathrm{~mm}$ & $28^{\circ}$ \\
\hline Mandibular Length (Go-Pog) & $73 \mathrm{~mm}$ & $26^{\circ}$ & $26^{\circ}$ \\
\hline FMA & $25^{\circ}$ & $30^{\circ}$ & \\
\hline SN-MP & $29.5^{\circ}$ & & \\
\hline
\end{tabular}

Table 2:- Dental Changes

\begin{tabular}{|c|c|c|c|}
\hline & \multicolumn{3}{|c|}{ CASE 1 } \\
\hline Pre (T0) & $\begin{array}{c}\text { Prefunctional } \\
\text { (after space closure) (T1) }\end{array}$ & Post (T2) \\
\hline U1-NA & $5 \mathrm{~mm}$ & $4 \mathrm{~mm}$ & $4 \mathrm{~mm}$ \\
\hline U1-NA & $32^{\circ}$ & $30^{\circ}$ & $29^{\circ}$ \\
\hline U1-SN & $111^{\circ}$ & $110^{\circ}$ & $67^{\circ}$ \\
\hline L1-NB & $5 \mathrm{~mm}$ & $5 \mathrm{~mm}$ & $26^{\circ}$ \\
\hline L1-NB & $21^{\circ}$ & $22^{\circ}$ & $98^{\circ}$ \\
\hline L1-IMPA & $96.5^{\circ}$ & $98^{\circ}$ & \\
\hline
\end{tabular}

Table 3:- Soft tissue Changes.

\begin{tabular}{|c|c|c|c|c|}
\hline \multicolumn{2}{|c|}{} & \multicolumn{3}{|c|}{ CASE 1 } \\
\cline { 3 - 5 } \multicolumn{2}{|c|}{} & Pre (T0) & $\begin{array}{c}\text { Prefunctional } \\
\text { (after space closure) (T1) }\end{array}$ & Post (T2) \\
\hline \multirow{2}{*}{ E Line } & Upper lip & $-3 \mathrm{~mm}$ & $-3 \mathrm{~mm}$ & $-4 \mathrm{~mm}$ \\
\cline { 2 - 5 } & Lower lip & $-2 \mathrm{~mm}$ & $-2 \mathrm{~mm}$ & $-2 \mathrm{~mm}$ \\
\hline $\begin{array}{c}\text { Nasolabial } \\
\text { angle }\end{array}$ & & 110.5 & 110.5 & 110 \\
\hline
\end{tabular}




\section{Bibliography:-}

1. Kharbanda OP. Orthodontics: Diagnosis and Management of Malocclusion and Dentofacial deformties. 2nd ed.: Elsevier; 2013.

2. Proffit WR, Fields HW, Sarver DM, Ackerman JL. Contemporary Orthodontics. Fifth Edition ed.: St Louis Mosby: Elsevier; 2013.

3. Kuhlberg AJ, Glynn E. Treatment planning considerations for adult patients. Dent Clin North Am 1997;41:1727. 